\title{
Disaster Management in Nepalese Context: An Ecological Perspective
}

\section{Kabi Prasad Pokhrel}

Professor of Environmental Geography, CDOGE, Tribhuvan University, Kirtipur- Kathmandu

\author{
"Correspondence author \\ Kabi Prasad Pokhrel \\ Professor of Environmental Geography \\ CDOGE \\ Tribhuvan University \\ Kirtipur- Kathmandu \\ Nepal
}

Submitted : 21 Sept 2020 ; Published : 17 Oct 2020

\begin{abstract}
This paper attempts to identify major natural hazards and disaster incidents damage and losses in Nepal. Using participatory and geographical diversity approach and for collecting information, multi-criteria decision making methods and analytical hierarchic process to identify the hazard prone area with type and intensity and location-specific innovative practices and their legitimization for integrating local and skills knowledge into mainstream development policy, science and technology through educational assessment to incorporate local knowledge as live science for disaster management, climate change adaptation and sustainable livelihood improvement. Findings of the study reveal that their varieties of natural hazards, such as landslides, flood/inundation, droughts, soil erosion, earthquakes, thunderstorm/lightening and fire which are exacerbated by environmental degradation processes. There are location specific local practices for resources conservation, utilization and disaster management for the well-being of communities before, during and after disasters. Such practices passed on from one generation to the next without integrating into mainstream development strategies, disaster policy and science. Ecology knowledge and local skills and materials for hazard prevention and mitigation have the important role to mitigate the hazards and ensure the sustainability for community life style. Further, study forwarded an action-oriented model i.e. political-ecological framework for the environmental resource conservation, disaster management and climate change adaptation practice in mostly vulnerable locations of Nepal. Moreover, measures are suggested to enhance the community capacity for managing their livelihood resources and disaster at the community level with proper integration of local knowledge with science and mainstream development policy.
\end{abstract}

Keywords: Political -ecological framework, disaster incidents, local knowledge and practice, hazard prone locations, and innovation and development

\section{Introduction}

Landslides, droughts, soil erosion, earthquakes thunderstorms, cold waves and floods are main natural hazards that occurred frequently and intensity ofmany of these hazards are exacerbated by environmental degradation processes in the different locations of Nepal. Social factors such as poverty, conflict and inequality excavated these incidents. Every year, the country experiences number of disasters. As a consequences Nepal ranks at $4^{\text {th }}$ position in terms of relative vulnerability to climate change, $11^{\text {th }}$ spot for earthquake vulnerability, $20^{\text {th }}$ topmost disaster-prone, and $30^{\text {th }}$ position in weather induced hydrometeorological disaster in the world [1]. Number of rural and urban communities in Nepal are number of populations is at the risk of climate change vulnerabilities. As a result, Nepal loses large portion of its gross domestic products (GDP) annually

at federal, province and local levels due to climate change -induced hydro-meteorological disasters with heavy loss of human life and physical property. The rising trends of different types of natural hazards and socio-economic vulnerabilities are resulted by ignoring the ecological sensitives into mainstream development policy and activities.

Efforts to mitigate the impacts of hazards and climate change often tend to focus on infrastructural development such as river embankment, river training, or on high-tech solutions such as sophisticated early warning systems based on scientific data and models. These solutions save lives when hazards affect communities; however, they need to be complemented by actions to address the underlying components of vulnerability 
the interrelated human, social and cultural factors that influence risk and contribute to turning a hazard into disasters. An important component that addresses such factors and that can increase the resilience of communities is their local knowledge. It has been clearly reflected in the Hyogo Framework for Action 2005-2015 (HFA) and, more recently, in the Sendai Framework for Disaster Risk Reduction 2015-2030 (SFDRR). The latter clearly acknowledges traditional and indigenous knowledge and cultural heritage as a fundamental resource to build a culture of safety and resilience at all levels. SFDRR strongly stresses the need to ensure the use of traditional, indigenous and local knowledge and practices to complement scientific knowledge in disaster risk assessment and the development and implementation of policies, strategies, plans and programs of specific sectors [2]. Participation and integration of communities in all disaster risk reduction (DRR) processes is necessary in pursuing the objectives of the framework in high sensible geographical area like Nepal for promoting sustainable development through better disaster risk reduction policies and practices [3].

Asian communities are thus extremely vulnerable to disasters, which are caused by natural hazards such as earthquakes, cyclones, droughts, landslides, and floods in combination with environmental degradation such as deforestation, desertification, biodiversity loss, pollution and soil erosion, as well as social factors such as poverty and inequality[4]. Their vulnerability is also affected by political and economic conditions, and the structure and organization of their societies.

Disaster Risk Reduction \& Management Act (2017) in Nepal has made paradigm shift from reactive to proactive engagement for disaster risk reduction and management (DRRM) for strengthening legal frameworks, policy and planning, organizational aspects, institutional capacities and partnerships for DRRM. The Constitution of Nepal has set the policy of disaster risk reduction, early warning, disaster preparedness, rescue, relief and rehabilitation for safeguard \& sustainable development to minimize the risks from disasters caused by natural hazards. Schedule 7 of the constitution has enlisted natural and non-natural disaster risk reduction, preparedness, and rescue, relief and rehabilitation activities in the concurrent powers of three level governments as per the spirit of the constitution. The constitution devolves power and resources to provinces and local governments for mainstreaming DRR and $\mathrm{CC}$ across three tiers of periodic planning, budgeting and implementation to adopt the risk informed development practices. The National Disaster Risk reduction Policy 2018 and Strategic National Action Plan (2018 - 2030), consistent with Sendai Framework for Disaster Risk Reduction (SFDRR) priorities have paved out wider opportunities to work with three level governments system of governance which is a new roadmap for Nepal till 2030 as a second paradigm shift to set out various targets, priority actions and activities .However, the policy and strategies of National Disaster Risk Reduction focus to curative measures for post damaged assessment and not emphasize preventive strategic measures and not address the proper link up of local knowledge and indigenous practices with science and technology in order to mainstreaming DRRM [5].

Authors emphasized to integrate local practice and ecological into science for

1. identify knowledge that can be integrated with science, which could then be further disseminated for use by scientists, practitioners and policy-makers, and

2. safeguard and valorize those that cannot be scientifically explained[4]. This process can enable communities to increase their resilience against the impacts of climate change and disasters.

Political-ecological approach has become increasingly important as a fundamental attempt to eco-development and environmental safeguard. It is imperative to consider ecological approach in the twenty-1st century for a greater understanding of natural hazards and disasters incidents. Thus ecological approach to development and disaster management is becoming the wider debates on disaster policies, science and education as well as development agendas and singles to consider environmental sensitivities and eco-development strategies through respect for local and indigenous approaches in coordinating alliances, culturally appropriate incentives accurate, appropriate, and ethical data base, acknowledgment of local and indigenous land use practices; use of indigenous language, leadership, and institutions; collaboration with indigenous knowledges, and acceptance of traditional approaches [6].

Geographical diversity alien with ecological approach as the multi-faceted arrays of knowledge, knowhow that guide societies in their innumerable interactions with their natural surroundings that interplay between people and place has given rise to a diversity of spatial-ecological systems that are at once empirical and symbolic, pragmatic and intellectual, and adaptive [7]. It is important to address the spatial relevance to cope the potential adaptation strategies as useful instrument for the cost-effective, participatory, sustainable and for resilience building efforts.

Since the 1970s, ecological approach to development and environmental management practices have been implementing to improve the quality of environment and disaster preparedness activities, notwithstanding these evidences, the marginalization of ecological principles in growth economy and environmental issues like resource degradation, climate change, natural hazards and disaster incidents, and environmental pollution are continued in dramatic pattern. Actually, it is composed of different knowledge types, practices and beliefs, values, and worldviews. Such systems change constantly under the influence of power relations and cross-scale linkages both within and outside the community which is required to understand as adaptive responses to internal and external changes which result (or not) in resource management and disaster preparedness at local level. Thus, need is to focus on people's ability to observe their surroundings, people's anticipation of environmental indicators, people's adaptation 
strategies, and people's ability to communicate about natural hazards within the community and between generations in order to identify their traditions, and practices which further needs to be understood within the broader context of livelihood security and sustainability and building up community resilience in the long term. It is, therefore, integration of local practices into eco-development and disaster management methods and practices should a process of blending these knowledge systems into a rational decision-making, sharing of information and understanding of different viewpoints between the indigenous people and the western trained professionals [8]. Disaster management as being a mutual take and give back to nature for the benefit of all components of the supporting socio-economic system and ecosystem such duty is for each of the creation from the communities to the powerful political organization and the spirits.

Authors viewed that scientific knowledge is fast becoming an integral part of disaster management, and, in the process, is changing the role of science for the reduction of disaster risks at the policy level [9]. However, the epistemological, institutional strategic scientific and policy operation gaps e in different domains between which there are often competing interests and modes of valuing local practices with respect to the interface between science and policy for environment/ social safeguard These gaps can help to explain underlying systematic challenges for the integration between science and policy for environmental stewardship and addressing changes at the governance level. Hence, the changing role of science vis-à-vis environmental safeguard and disaster management and risk reduction are intrinsically tied to how ecology stability is perceived culturally and politically.

Authors emphasized to increase citizen engagement in science and policy decisions at different scales of governance that move beyond tokenistic forms of citizen participation and offered a framework for citizen social science (CSS) an advanced collaborative approach of accelerating climate action and policies that moves beyond conventional citizen science and participatory approaches [10]. The implications of increased citizen action through CSS can inmove the broader normative and political paradigm of multidisciplinary and co-productive climate change research [11].

Author perceived that natural hazards and environmental management initiations need to develop capacity in multihazards risk assessment and to provide a platform for enabling intra-community interaction and exchange of knowledge, skills and experiences to generate greater awareness of how and in what ways environmental safeguard can be assured and natural hazards could be mitigated [12]. This demands to understand and integrate local knowledge into science and technology for the effective disaster preparedness at the local context where people can be able to save their lives and property. A better understanding of local practices and contexts helps to better plan for disaster management and to build the community building with acceptance, ownership and sustainability as well as cost-effectiveness in long-term.
However, many implementing organizations have ignored the value of local knowledge for success and sustainability and the meaning of local knowledge on environmental safeguard and the methods to identify and collect information related to it. Authors argued that enhancing the interfaces among education, science, technology, and policy making and the development and implementation of innovations techniques effectively [13]. They stressed on science-society partnership models for identifying and implementing options that manage critical environmental issues like disaster risks on the ground. This particularly holds true for debate around loss and damage with due consideration of experiences that exist [14]. The area of spatial information technology (GIS, RS, GPS) has equally important for mapping location-specific resource strengths, natural hazards prone areas, warning and response. Such digital data tools have been revolutionizing potential capacity to analyze hazards, risks and vulnerability, and plan for sustainable livelihood improvement including disasters management. Environmental planners need extensive databases relating to needs (for example of vulnerable people and their locations) and resources such as human capacities and emergency equipment). Authors [15] reported that education as an important component of disaster management in relation to identify the hazard prone locations, disaster preparedness, prevention and response and information on predicting. Thus, the focus of the twenty first century need to be emphasized to equipped people by ecological understand and moral ground with the capacity to lead meaningful and productive lives in a world of rapid and complex change. Th role and meaning of education thus, should be its socio-cultural and ethical dimensions stressing on learning to live together in which integrating the concerns and issues of living together adopting the mainstream policy and science to cope with issues and challenges raised by the drivers of change like environmental change (resource degradation and climate change hazards) globalization and population dynamics.

Regarding above mentioned issues and options at global and national level on adopting ecological approach to sustainable livelihoods improvements and natural disaster management integrating local practices into policy and science the aim of the paper is to discuss the causes and consequences of ignoring ecological sensitives in development process in Nepal and also point out the damage and losses of unsustainable development practice that resulted through natural hazards such as landslides, flood/inundation and soil erosion.

\section{Approach and Methodology}

The adopted methodology composed of desk study, natural hazards prone area observation, location specific prone area mapping through GIS, GPS techniques, households survey in natural hazard affected communities, consultation meetings, FGDs, and key informant's interviews were applied for identifying local practices for disaster management, point out the policy, strategic plan and actions.

Multi-hazard focus approach was used to identify hazards 
locations, prevention practices, policy practices and, strategic plans with the due consideration local ecological knowledge system to map out the causal interconnection of spatial forces as what people know is influenced by (and influences) their beliefs, lifestyle, and behavior and local which helped to understand and account for people's ways of knowing as their practices and beliefs, perceptions, and values on disaster management with technical skill application for conservation, utilization, construction and combination of specific materials for domestic and local buildings. Local, technical knowledge included environmental sociocultural and historical knowledge to understand people's livelihoods and their worldviews which further helped to identify local to ability to observe surroundings, adaptation strategies, anticipation of environmental indicators, ability to communicate about natural hazards and ability to prepare preparedness plan and understand the broad context of sustainable livelihoods and community resilience building $(\mathrm{CRB})$. Risk reduction approach was applied for the policy frameworks and action plans which emphasized on risk reduction rather than relief and rescue. The most affected sectors like agriculture, livelihood, shelter, health, education, infrastructure, water supply and sanitation, tourism, civil aviation, and information and communication were identified. Through multi-sector approach. Geographical diversity approach was considered to trace out natural disaster risks that manifested differently across different geographies, the same disaster risk reduction action has different practical manifestations across different geographies. The core issue, besides finding solutions to physical and economic dimensions of disaster risk reduction, is one of avoiding cultural invasion that so often comes as part of the package with technologically advanced disaster management solutions. (figure-1).

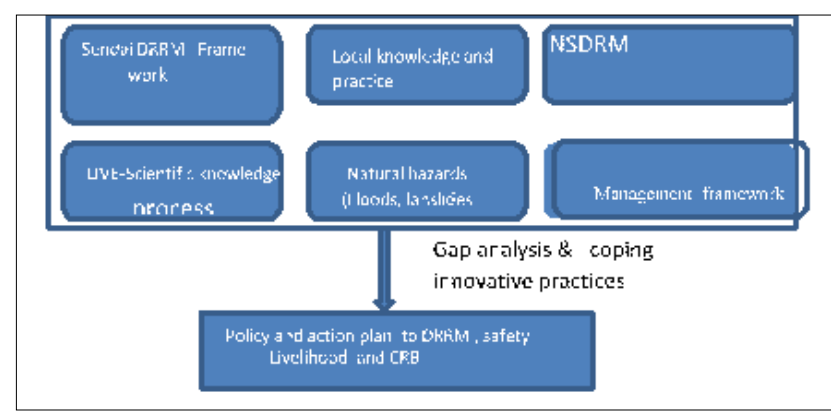

Figure 1: Adopted Methodology

This methodological framework was used to review local knowledge practices for natural hazards prone location identification, national strategies for disaster risk management and practices for integrating local practices with scientific skills and techniques to enhance capacity for safe and sustainable livelihood and community resilience building of local people.

\section{Research gap}

Most of the actions, initiations and policy provisions that implemented at national, province and local level in Nepal are curative in nature for post damage assessment adopting conventional modality and preventive measures for hazards management and neglected environmental sensitives into mainstream development policy Thus, need is to adopt ecological approach to development practice integrating local practices with science and mainstream development policy for the effective initiations taken by locals. Issues and challenges appeared in the field of natural hazards management and improvement of sustainable livelihoods of community people shows the need of an innovative research at local level to identify the local/indigenous knowledge, skills and practices and frame out the plan and policy schemes for the integration of local and indigenous skills with mainstream policy and science in order to build capacity of community people to prevent climate induced multi-hazards and sustainable livelihoods.

Challenges with respect to the integration of scientific knowledge in disaster risk reduction plans and practices enforced to streamline the underlying institutional and systemic issues of governance at local national and global levels. These issues require innovative solution through the academic exercise to explore what kind of knowledge is presently sought after by policymakers and disaster management practitioners, what the present needs and gaps in knowledge production are from the perspective of the scientific domain, and what the balance is between public risk awareness and existing knowledge that informs policy and governance levels. Major issues relating with integrating local and indigenous knowledge remain as the central theme for academic research which should identify the barriers to the transfer of knowledge, a lack of disaster expertise, and persistent issues related to raising risk awareness. These research issues clearly indicate an epistemological gap, that is different in understandings of which types of knowledge are relevant and need to be managed; a strategic gap, that is a lack of common understanding of how to strategically use scientific and expert knowledge for disaster risk reduction planning; and an institutional gap, that is the need for institutions and organizations that are able to absorb and transform expert knowledge. Innovative research stands as the proactive solution for addressing central factors that help explain current challenges facing the science-policy interface for disaster risk reduction. Thus, the concentration of this innovative research is to discuss the integration of science and policy for disaster risk reduction with respect to these three gaps at the level of governance focusing on the interface and relationship between science and policy in the context of disaster risks and also discuss the role of science for policy. Previous researchers reveal that knowledge is being transferred to an imagined policy domain should depart from the perspective that the interface between science and policy is shaped by a range of competing interests from multiple actors academic, political, and bureaucratic. Indeed, frictions and tensions that are endemic to science-policy interfaces writ large are also impacting the role of science for policy and decision making for disaster risk reduction throughout world.

\section{Multifaced hazards}

The geological structure, geomorphic process of Nepal Himalaya and ignorance of ecological sensitives into mainstream development activities have created the situation of multi hazards geography and disaster incidents throughout the country. The disaster incidents killed large number of lives, caused huge amount of economic loss and damaged billions 
of physical infrastructures in every year. Physical geography, geological structure and the impact of climate change are being the prime factors that brought out dramatic changes in natural settings and causing to natural disasters. The rate and intensity of natural hazards are in increasing trends due to anthropogenic activities such as haphazard and unplanned development activities, ruthlessly extraction of environmental resources and over dependency environmental resources for the livelihood of poor people. Aggregately, both natural and socio-cultural factors and forces led to the environmental degradation, disaster incidents and vulnerabilities in the different parts of the country [16]. The major disaster incidents that caused due to the heavy rainfall during the monsoon period June- August, 2020 are discussed here as the main consequences of negligence of ecological sensitives into mainstream development policy.

\section{Major disaster incidents in Nepal}

Nepal has been facing varieties of disaster events such as floods, landslides, lightning, fire, cold wave, heavy rainfall, thunderstorm, epidemic, snakebite, snow storm, avalanche, hailstone and others. These incidents caused the loss of hundreds of lives and billions of Nepalese rupees. Monsoon and pre-monsoon related disasters like fire, thunderstorm/ lightning floods, landslides, debris flow inundation, and heavy rainfall claimed most of the lives. Among them landslides and floods have occurred during the monsoon period i.e. June to August and damaged billions of physical properties and killed hundreds of people. These natural hazards are rising on since last decades due to the ignorance of ecological aspects into the main stream of development during the time of physical infrastructure development and construction works. The weak geological structure and unstable geomorphic process of the whole pars of the country, Nepal is likely vulnerable for natural disaster and the rate and frequency of disaster incidents increased by the tradition of non-technical process of physical infrastructure like road construction, extension of electricity line and other construction works. Landslides incidents across the country clearly indicate that the natural disasters caused losses and damage are directly interrelated with physical infrastructure development activities which further show that the physical development plans and programs of the country are not considered the ecological value and ethical responsibilities by the government authorities [17\&18]. During the time of Sindhupal chock Lidi landslide slide observation local people reported that the politicians have pressured to design and plan the development programs according their self-interest and ignored the ecological aspects. Due to the political pressurized development tradition, we (community people) are suffering by disaster incidents every year (Photograph-1 and 2).

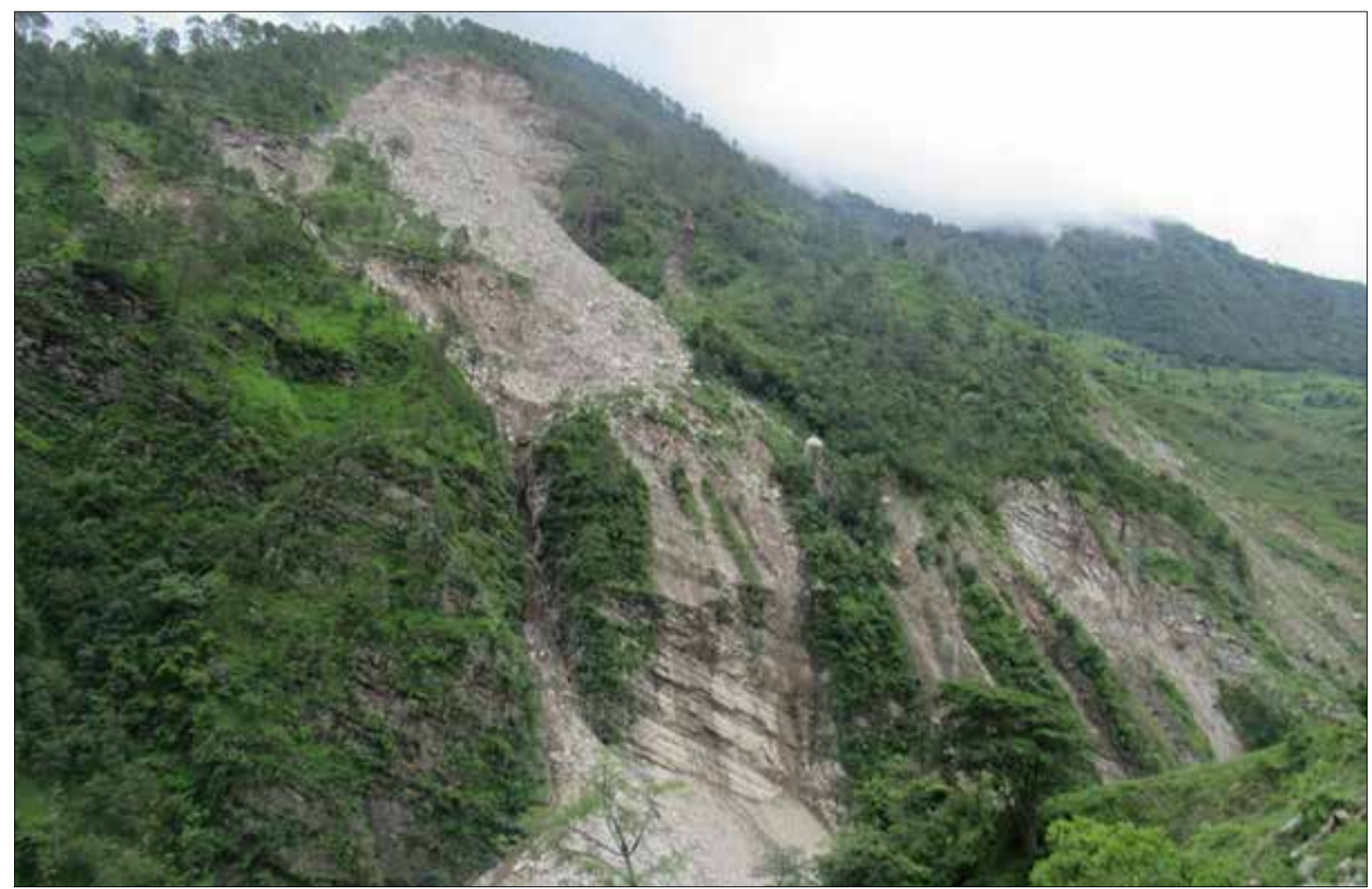

Photograph 1: Landslide Badimalika, Bajura of Sudur Paschim Province where 60 households were displaced after a landslide in July, 2020. 


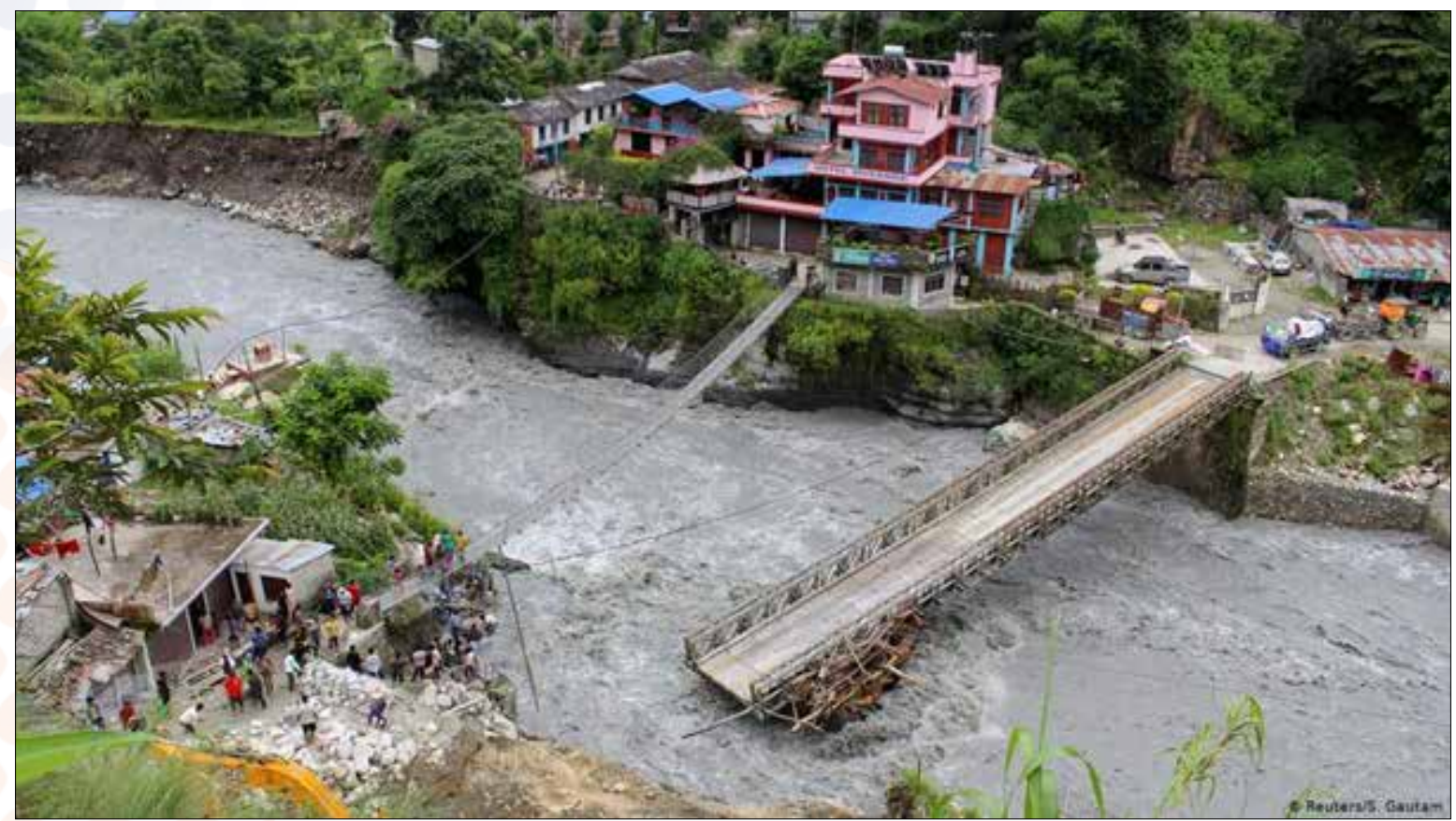

Photograph 2: Huge physical and human properties losses by landslides in Lidi, Sindhupalchock, Bagmati Pradesh

It is indicative that from the figures 1 and 2 landslide incidents is most destructive disaster for Nepal. Almost all hilly and mountain areas of the country affected by landslide however, the nature, intensity and trends are varied from east to west and north to south. Landslides of this year monsoon killed more than 60 people and damaged huge amount of physical properties in a single location i.e. Lidi of Sindhupalchock district and Badimalika in Bajura district Therefore, hazards incidents losses and damaged recorded in different scales in different geographical regions and provinces. Landslide observed as the main disaster in hilly and mountainous regions whereas floods/inundation and fire found more in low land area i.e. tarai plain. Similarly, lightening/thunderstorm found to increasing incident in all parts of the country. The province wise disaster incidents found varied such as landslide is much more in No.5, Gandaki Pradesh, Sudur Paschim Pradesh and No 1 Pradesh. Whereas the incidents of flood and lightening observed more in No.2 Pradesh, Bagmati Pradesh and Sudur Paschim Pradesh. The major disaster incidents frequencies are presented in table 1 .

\begin{tabular}{|l|l|l|l|l|l|l|l|}
\hline S.No & Province & $\begin{array}{l}\text { Floods/ } \\
\text { Inundation }\end{array}$ & $\begin{array}{l}\text { Landslides/ } \\
\text { Debris flow }\end{array}$ & $\begin{array}{l}\text { Lightening/ } \\
\text { Thunderstorm }\end{array}$ & Fire & Total & $\%$ \\
\hline 1 & No.1 & 12 & 69 & 32 & 60 & 163 & 14.97 \\
\hline 2 & No.2 & 30 & 3 & 40 & 120 & 223 & 20.48 \\
\hline 3 & Bagmati Pradesh & 16 & 68 & 25 & 45 & 134 & 12.30 \\
\hline 4 & Gandaki Pradesh & 11 & 77 & 20 & 18 & 126 & 11.57 \\
\hline 5 & No.5 & 9 & 81 & 45 & 50 & 185 & 16.98 \\
\hline 6 & Karnali Pradesh & 8 & 62 & 23 & 35 & 128 & 11.75 \\
\hline 7 & Sudur Paschim Pradesh & 15 & 67 & 18 & 30 & 130 & 11.93 \\
\hline 8 & Nepal & $101(9.27 \%)$ & $427(39.21 \%)$ & $203(18.64 \%)$ & $358(32.87 \%)$ & 1089 & 100.00 \\
\hline
\end{tabular}

Source: National Emergency Operation Center (NEOC) /MOHA/GON, 2020

Table 1: Major disaster incidents by province During Monsoon period June- August, 2020)

Table 1 exhibits that in an average Province No 2 is more vulnerable from the aggregate disaster incidents. Fire, floods/inundation and lightening/ thunderstorm badly effect in Terai whereas Gandaki Pradesh is in low risk in aggregate incidents. But in landslides disaster, Province No 5, Province No 1, Gandaki Pradesh Sudur Paschim Pradesh, Bagmati Pradesh and Karnali Pradesh are much more vulnerable. The death toll due to land slides disasters is greater in hilly and mountainous areas whereas the death and losses of properties in the Tarai. The total death, missing people, injured people and number of affected families due to different disaster incidents are presented in table 2 . 


\begin{tabular}{|l|l|l|}
\hline S.No & Description & Quantity/ amount \\
\hline 1 & $\begin{array}{l}\text { Total number of } \\
\text { incidents }\end{array}$ & 1089 \\
\hline 2 & Death: & \\
& Male & 170 \\
& Female & 140 \\
& Total & 317 \\
\hline 3 & Missing people No & 76 \\
\hline 4 & Injured people No & 424 \\
\hline 5 & Affected family No & 2139 \\
\hline 6 & Damage house No & \\
& Partial & 880 \\
& Complete & 327 \\
\hline 7 & Estimated losses (NRs) & $402,297,650$ \\
\hline
\end{tabular}

Source: National Emergency Operation Center (NEOC) MOHA /GON,2020

Table 2: Damage and losses of disaster incidents (During June $\&$ August, 2020)

It is evident from the table 2 that 310 people were died during monsoon period i.e. June -August, 2020. 76 people were missing and 424 people were injured from the landslides and flood/inundation disaster incidents. Whereas 327 houses were completely damaged and the number of partial damage house was 880 . Affected family number recorded 12139 . In total around NRs402,297,650 losses were recorded.

\section{Ecological model for disaster management}

The Political- ecology framework (Figure 2) has been forwarded for the effective management of natural disasters and sustainable livelihood improvement in the disaster-prone area. Generally, political ecology considers as a loose bundle of theories which analyze environmental issues from a wider political point of view that also investigates how the cultural, ecological, social and political issues conflate in environmental issues such as environmental resources degradation and biodiversity decline $[19 \&$ 20]. Author stated that the recognition of different positions, perceptions, interests and rationalities among different actors interested in conservation of environmental resources including wetland and biodiversity is a prerequisite for a successful management of disasters and use of natural properties [21]. In fact, ecology being a broad concept that encompasses social, economic, ecological and political aspects, its management, uses and conservation should, therefore, consider the broad nature of the concept, which makes the political ecology model the most appropriate in critical analysis of the conservation of environmental resource and effective disaster management.

The choice of the actor-oriented approach, among several other approaches of political ecology, gets support from [22 \&23]. who argue that an actor-oriented approach i.e. ecological framework is useful when dealing with several actors interested in a certain aspect such as resource conservation and disaster management, as it emphasizes discussions on plurality of actors who are related to conservation interventions as well as their socio-economic characteristics, perceptions and the political influence that occurs between the actors: these differences affect access to and control over spatial patterns among different actors.

Author regarded it as a social processes in which environmental citizens are the actors with different interests and unequal power among them which determine the outcome of the conservation and management process [24]. Such relations, however, rarely have been taken care of. This indicates that power relation among members of a social group determines individuals and household level activities and actions and interactions with their supporting ecosystem. Ignoring the perpetuation of unequal power relations between indigenous people and other actors has been limiting integration of the local knowledge into other forms of knowledge systems as such power imbalance has been fostering rejection of the local ecological knowledge system its transformation and its integration into ways of knowing and doing.

The actor-oriented model has also considered to take into account that the nature of the spatial characteristics and behaviors of locals with individual actions in value systems and social norms which shaped by the social context, through a social standard of evaluation of actions, strategies and outcomes of their actions. The actions and strategies of the social group are determined by social networks, social controls and social hierarchies aimed at ensuring social security balances necessary for the survival of the group and of their ecosystem. Based on that, the actor-oriented approach could be used for critical analysis on the relationships between different actors within different socio-economic and political contexts that determined their interaction with their supporting sociopolitical system in the existing ecological conditions. Such interactions determined the community level disaster management and use of available resources at their locality [25]. Moreover, understanding of the existence of social structures, networks and power relation within and between actors is the cornerstone for collective and comprehensive strategies and practices for community building resilience and sustainable livelihood improvement (figure 2).

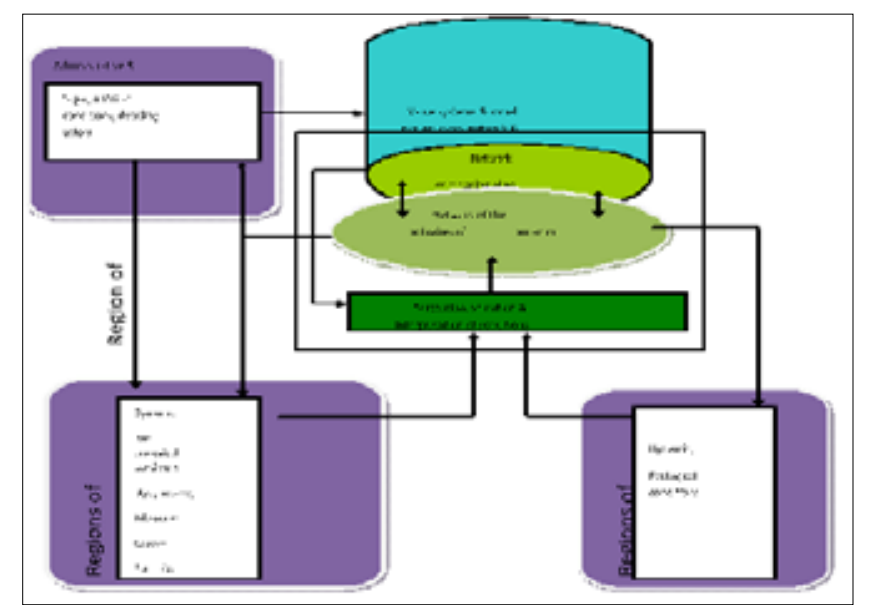

Figure 2: Political- ecological approach to eco-development and disaster management 
Way forward

- Government efforts are required to ensure ecodevelopment and disaster governance at all level of government.

- Development and management paradigms need to shift from central controlled to bottom up initiation to ensure the coherence among the sectoral policies and strategic development plans for environment, economy and social security in close and proactive engagement of governments, academic institutions and stakeholders of the community building resilience.

- Disaster management funds need to be established in three tiers of governments with a clarity on mobilization of the funds effectively.

- Risk assessments system have to institutionalized in a collaborative/ participatory framework adopting politicalecological approach to understand the severity of hazards to foster evidence-based environmental risk sensitive disaster management and livelihood improvement development planning for the disaster-prone areas.

- The minimum requirements of the assessments, hazard specific standards should be agreed based on scientific practices and local ecological as well as cultural grounds.

- Efforts should focus participatory approaches in planning, preparedness, response and rehabilitation.

- Appropriate policy and plan strategies have to be developed to address the disaster displacement people and community.

- Disaster management related information, its accumulation, establishing common platform and ensuring access to all is a key concern, so that disaster information management system (DIMS) needs to be established and institutionalized at all government level

- Mainstreaming eco-development and disaster management into national development policy is the need of the time for achieving sustainable development goals so that disaster risk and impact assessment need to be incorporated in mainstreaming development plan and programs.

- Efforts are required to apply political ecological approach to sustainable development and disaster management with the collaboration of public institutions, private sector and and people at large for the disaster management and sustainable livelihood improvement.

- Local cultural capital, ecological resources and knowledge, skills and technology safety actions need be promoted through formal, informal and nonformal education system.

\section{Conclusion}

Nepal is at high risk of geo-climatic and physical hazards and has facing varieties of disaster events such as floods, landslides, lightning, fire, cold wave, heavy rainfall, thunderstorm, epidemic, snakebite, snowstorm, avalanche, hailstone and others. These incidents caused the loss of hundreds of lives and billions of Nepalese rupees. Monsoon and pre-monsoon related disasters like fire, thunderstorm/ lightning floods, landslides, debris flow inundation, and heavy rainfall claimed most of the lives. There are location specific local practices for resources conservation, utilization and disaster management which are key to the security and wellbeing of communities before, during and after disasters. Such practices passed on from one generation to the next without integrating into mainstream development strategies, disaster policy and science. Their ecological knowledge, practices, and technologies and materials for the safety of environment and hazard prevention and mitigation have the important role to ensure the sustainability for community life style. Thus, spatio-temporal need is to promote the local ecological i.e. indigenous knowledge, practices and experiences with the proper integration with main streaming development policy and science for the effective environmental resource conservation, disaster management and sustainable livelihood improvement at national and local level.

\section{References}

1. National Emergency Operation Center (NEOC) (2019) Nepal disaster report-2019. Kathmandu: MOHA/GON

2. United Nations (UN). (2015) Sendai Framework for Disaster Risk Reduction (2015-2030). United Nations Economic and Social Commission for Asia and the Pacific (UNESCAP) (2012). Statistical yearbook for Asia and the Pacific. Available on line from:http://www.unescap.org/ stat/data/syb2012/ index.asp); 2012[accessed14.09.13].

3. 3. UNDRR (2019) Disaster Risk Reduction in Nepal: Status Report 2019. Bangkok, Thailand: United Nations Office for Disaster Risk Reduction (UNDRR), Regional Office for Asia and the Pacific

4. United Nations Economic and Social Commission for Asia and the Pacific (UNESCAP) (2012). Statistical yearbook for Asia and the Pacific. Available on line from: http://www.unescap.org/stat/data/syb2012/ index.asp); 2012[accessed14.09.13].

5. Ministry of Home Affairs (MOHA). (2018). Risk reduction policy 2018.Kathmandu: MOHA

6. Lambert S J, Scott J C, (2019) International Disaster Risk Reduction Strategies and Indigenous Peoples. The International Indigenous Policy Journal, 10(2). Retrieved from: https://ir.lib.uwo.ca/iipj/vol10/iss2/2 DOI: 10.18584/iipj.2019.10.2.2

7. MoSTE (2015) Indigenous and Local Knowledge and Practices for Climate Resilience in Nepal, Mainstreaming Climate Change Risk Management in Development, Kathmandu: Ministry of Science, Technology and Environment (MoSTE).

8. Ruheza, S and Khamis, Z. K. (2012) Integration of the indigenous knowledge and scientific systems for conservation of biodiversity: significances of their different worldviews and their win-loss relationship. Journal of Sustainable Development in Africa 14(6): 160174.

9. Albris K, Lauta K C, Raju E (2020) Disaster knowledge gaps: Exploring the interface between science and policy for disaster risk reduction in Europe. Int J Disaster Risk Sci Volume 11: 1-12 . https://doi.org/10.1007/s13753-02000250-5 
10. Kythreotis AP, Mantyka-Pringle C, Mercer TG, Whitmarsh LE, Corner A, Paavola J, Chambers C, Miller BA, Castree $\mathrm{N}$ (2019). Citizen social science for more integrative and effective climate action: A science-policy perspective. Front. Environ. Sci. 7: 10.doi: 10.3389/fenvs.2019.00010

11. UNMGCY. (2017) Youth science policy interface publication - Special Edition: Disaster risk reduction: A road of opportunities. Mexico: UN Major Group for Children and youths.

12. Pokhrel, K.P. (2015) University research on climate change adaptation and risk management. TU Bulletin Special : $62-70$

13. Rai P, Khawas V 2019 'Traditional knowledge system in disaster risk reduction: Exploration, acknowledgement and proposition', Jàmbá: Journal of Disaster Risk Studies 11(1): a484. https://doi.org/10.4102/jamba.v11i1.484

14. Mechler, Reinhard, Colin McQuistan, Ian McCallum, Wei Liu, Adriana Keating, Piotr Magnuszewski, Thomas Schinko, Finn Laurien, Stefan Hochrainer-Stigler (2018). Supporting Climate Risk Management at Scale. Insights from the Zurich Flood Resilience Alliance Partnership Model Applied in Peru \& Nepal. Loss and Damage from Climate Change: 393-424

15. Tiernan Anne, Lex Drennan, Johanna Nalau, Esther Onyango, Lochlan Morrissey, Brendan Mackey (2019). A review of themes in disaster resilience literature and international practice since. Journal of Policy Design and Practice, 2(1): 53-74.

16. Walsh, Sara (2017) Mainstreaming disaster risk reduction in Nepal: The rhetoric and the reality. Doctoral thesis, Northumbria University

17. Sarma K, Barik S K (2013) Landslide susceptibility zonation of Tawang District of Arunachal Pradesh using geospatial technology. Disaster and Development 7 (1\&2): 97-113, ISSN: 0973-6700 .

18. Danladi A (2019) Indigenous knowledge in flood disaster risk reduction in Kaduna town Nigeria. $\mathrm{PhD}$ dissertation submitted to Universiti Teknologi Malaysia.

19. Mélissa Généreux, Marc Lafontaine, Angela Eykelbosh (2019) From science to policy and practice: A critical assessment of knowledge management before, during, and after environmental public health disasters. Int $J$ Environ Res Public Health. Feb; 16(4): 587. Published online 2019 Feb 18. doi: 10.3390/ijerph16040587 PMCID: PMC6407109

20. Khor M, Lin L L (2016) Good practices and innovative experiences in the south: Citizen initiatives in social services, popular education and human rights, 3. London: Zed Book Ltd.

21. Marten G G (2008) Human ecology: basic concepts for sustainable development. UK: Earthscan publishers.

22. Basnayake S, Punyawardena BVR, Jayasinghe S, Gupta N, Shrestha ML, Premalal KHMS (2019). Climate smart disaster risk reduction interventions in Agriculture sector - Flood hazard - A practitioner's handbook .Japan: Asian Disaster Preparedness Center

23. TakakoIzumi, RajibShaw, RiyantiDjalante, TakeshiKomino (2019). Disaster risk reduction and innovations. Progress in Disaster Science 2: 100033 https://doi.org/10.1016/j.pdisas.2019.100033Get rights and content open access

24. Ranke U (2016). Natural Disaster Risk Management: Geosciences and Social Responsibility. Switzerland: Springer International Publishing

25. Wester P, Mishra A, Mukherji A, Shrestha AB, (eds) (2019) The Hindu Kush Himalaya Assessment-Mountains, Climate Change, Sustainability and People. Switzerland AG, Cham: Springer Nature
Copyright: (C2020 Kabi Prasad Pokhrel. This is an open-access article distributed under the terms of the Creative Commons Attribution License, which permits unrestricted use, distribution, and reproduction in any medium, provided the original author and source are credited. 